\title{
A BIOGEOGRAFIA NO CONTEXTO DAS AVALIAÇÕES DE IMPACTO AMBIENTAL
}

\author{
Bernardo Machado Gontijo (*)
}

\section{INTRODUÇÃO}

No âmbito da avaliação de impacto ambiental, o diagnóstico constitui-se em uma parte fundamental, sendo base para o estudo das diversas implicações que advêm da atividade impactante. No escopo dos estudos de impacto ambiental propriamente dito, o diagnóstico deve ser precedido pela delimitação da área de influência do projeto impactante e deve anteceder às etapas de prognóstico e de proposição das medidas mitigadoras.

Um problema que vem acompanhando a execução de tais diagnósticos, bem como os respectivos produtos (textos) que constam nos relatórios de impacto ambiental, resulta do caráter multidisciplinar que envolve tais tarefas. Este problema é particularmente perceptível em estudos que envolvem projetos de grande magnitude, realizados por empresas de consultoria ambiental preocupadas em abranger seriamente todas as variáveis envolvidas em tais empreendimentos. Em função do grande número de profissionais que, esperase, sejam envolvidos em tais estudos, com habilitações técnicas não raro bastante específicas, o produto final (descrição e análise dos recursos ambientais e suas interações) adquire um aspecto formal semelhante ao de uma "colcha de retalhos".
O coordenador geral de um Estudo de Impactos Ambientais (EIA) deve prestar especial atenção a este aspecto e, neste sentido, um profissional específico deveria ser incumbido de amarrar e homogeneizar os dados e informações coletados pelos diversos técnicos envolvidos. Este é um trabalho que um profissional em Geografia está especialmente habilitado em executar. Sua formação permite não apenas o conhecimento geral de diversos elementos da paisagem física e humana que devem ser analisados em qualquer EIA, como lhe concebe meios para espacializá-los e cartografá-los, em todas as escalas em que o estudo seja desenvolvido.

Considerando a estrutura geral de um diagnóstico, nos moldes que os órgãos estaduais de controle ambiental geralmente definem, devem ser considerados três meios sobre os quais irá se fazer o trabalho de levantamento e análise de dados referentes aos recursos ambientais da região a ser impactada, quais sejam, os meis físico, biótico e sócio-econômico (ou antrópico).Esta estrutura pode ser visualizada através do fluxograma apresentado na figura 1 . Com relação aos meios físico e sócio-econômico, os elementos a serem considerados são abordados, com maior ou menor detalhamento, nas grades curriculares dos cursos de Geografia, especialmente nas disciplinas usualmente

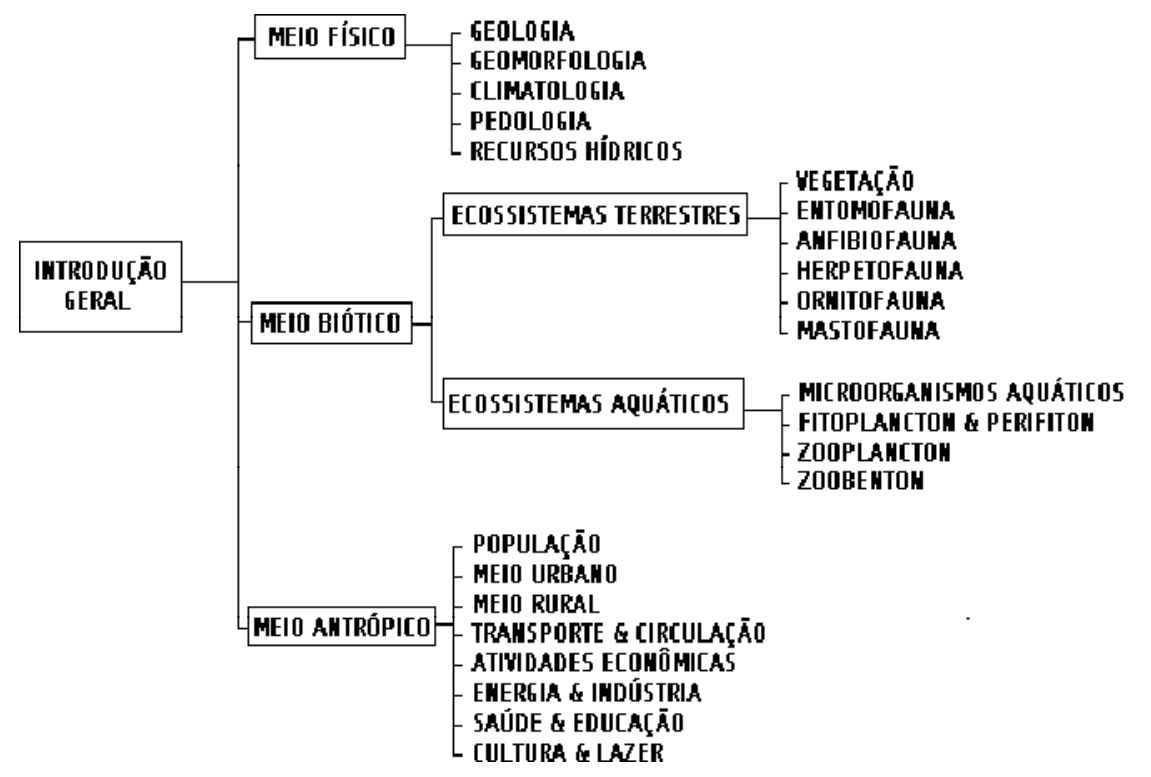

Figura 1: Estrutura, em termos de distribuição do conteúdo, de um Diagnóstico Ambiental Simples 
agrupadas no escopo da Geografia Física (no primeiro caso) e da Geografia Humana (no segundo caso).

Com relação à Geografia Física, devem ser considerados, no âmbito de um diagnóstico ambiental que se pretenda completo, conteudos referentes à climatologia, incluindo dinâmica atmosférica, análise de parâmetros meteorológicos a partir de dados de superfície, análise de qualidade do ar; etc.; à geomorfologia, incluindo topografia; processos denudacionais e deposicionais, áreas de risco, etc.; à hidrologia, incluindo rede de drenagem, regime hidrológico; qualidade da água, etc; à pedologia, incluindo análise de parâmetros físicos e químicos do solo, fertilidade e/ou oligotrofismo, potencial de aproveitamento econômico, etc.

Com relação aos elementos do meio sócioeconômico que devam ser abordados no âmbito da Geografia Humana, espera-se que sejam incluídos conteúdos referentes à geografia da população, incluindo análise de parâmetros demográficos diversos, estudos referentes à evolução temporal da população, pirâmide etária, movimentos populacionais, etc; à geografia urbana, incluindo infra-estrutura, hierarquização, urbanismo, etc.; à geografia agrária, incluindo análise de concentração fundiária, produção agrícola, uso do solo, etc.; à geografia econômica, incluindo aspectos ligados à circulação de mercadorias, aos níveis de emprego, à geração de renda, aos diversos setores da economia, etc.; à geografia da energia e indústria, incluindo análises relativas à localização industrial, às fontes de energia utilizadas, à origem da matériaprima transformada, etc.

Quanto ao meio biótico, por questões óbvias, este seria aquele campo a ser diagnosticado cujo conteúdo global é o menos relacionado à Geografia. Trata-se de um campo no qual os profissionais da área de Ciências Biológicas muito têm contribuído, especialmente com relação às diversas especificidades que o amplo espectro do mundo biótico comporta. Mas também com relação ao meio biótico percebe-se a contribuição potencial que pode advir do conhecimento geográfico, aqui no caso relacionado aos conteúdos constantes no programa da disciplina biogeografia. A biogeografia, neste sentido, surgiria como um elo de amarração para amalgamar o conteúdo, muitas vezes de caráter fragmentário, da maneira como o meio biótico, não raramente, tem sido apresentado nos Relatórios de Impacto Ambiental.

Como o campo de conhecimento das Ciências Biológicas é extremamente amplo, função da grande diversidade de seres vivos, especialmente em meio tropical como é o nosso caso, repete-se nos textos referentes ao meio biótico o mesmo problema relacionado àquela "colcha de retalhos" citada no início deste trabalho. Muitas vezes, para a execução de trabalhos consistentes, profissionais de diversas áreas do conhecimento biológico são chamados a contribuir com relação a conteúdos específicos de suas respectivas especialidades, as quais demandam estratégias metodológicas específicas e acabam por gerar produtos cujos resultados são expressos de maneiras bem diversas entre si, o que acaba por dificultar a compreeensão global do meio biótico estudado. É o que se observa quando se avalia os produtos gerados por um botânico (tabelas, transectos, gráficos, mapas temáticos simples, etc.) e os mesmos são comparados com as listagens de espécies, gráficos de barra e diagramas circulares tão usados por entomólogos, herpetólogos, ornitólogos e mastozoólogos; isto sem falar das tabelas e quadros fornecidos pelos microbiologistas e limnologistas quando de suas análises referentes aos meios aquáticos a serem impactados.

Além da multiplicidade de formas diferentes de expressão gráfica utilizadas, incluindo aí uma subutilização de recursos cartográficos que devem ser de conhecimento dos geógrafos, problemas mais graves tendem a surgir quando da obtenção e análise dos resultados. Como a abordagem metodológica para o estudo da flora e de cada grupo faunístico é diferente (o que é óbvio em função do papel ecológico diferenciado que cada grupo a ser analisado exerce no meio), corre-se o risco de obterem-se resultados que podem vir a ser contraditórios, ou até mesmo mutuamente excludentes. Certamente que isto refletiria abordagens errôneas ou metodologias inadequadas. Qualquer que seja o motivo que gere tais deficiências, são falhas que o coordenador geral do EIA no qual tal diagnóstico esteja inserido não pode deixar ocorrer, sob pena de comprometer a confiabilidade do trabalho.

Percebe-se, portanto, a importância de se procurar um elo metodológico que uniformize a linguagem no âmbito do meio biótico e, mais ainda, no âmbito de todo o relatório. Este elo metodológico pode ser buscado, em uma primeira instância, na própria biogeografia, que pode ser considerada como uma ciência que permite a ligação natural entre o estudo do meio biótico e o estudo do meio físico. Numa segunda instância, a própria Geografia estabeleceria a amarração metodológica de todo o diagnóstico uma vez que abrange, no seu escopo, a análise conjunta entre os meios físico (aí já incluindo o biótico) e o meio antrópico. Trata-se, como bem apontou CHRISTOFOLETTI (1981), da única ciência que mescla variáveis humanas com variáveis naturais. Procurar-se-á então, neste trabalho, delimitar-se este "elo metodológico geográfico"(e biogeográfico) o qual conferiria coerência e uniformidade ao corpo de um diagnóstico ambiental. Esta situação pode ser visualizada no fluxograma apresentado na figura 2 . 


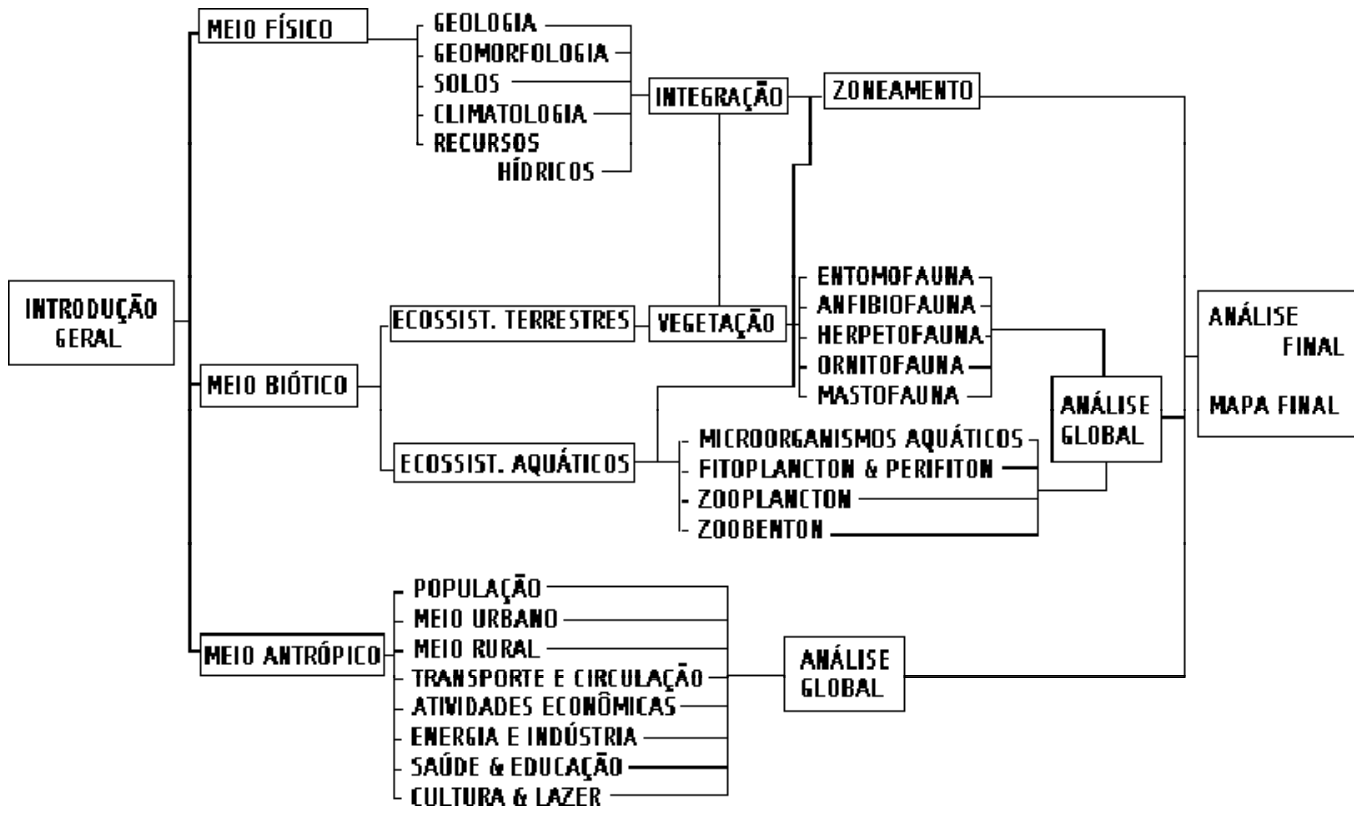

Figura 2: Estrutura geral de um Diagnóstico Ambiental uniformizado, no qual está inserido o "elo metodológico geográfico"

Uma rápida passada de olhos no fluxograma acima permite-nos visualizar a preocupação em uniformizar o conteúdo de cada um dos três meios, bem como a necessidade de se chegar a um produto final tanto na forma de texto como na de mapa. Percebe-se também a possibilidade de união entre os conteúdos do meio físico e do meio biótico, isto graças à perspectiva biogeográfica de análise.

A introdução geral não foge ao que deve ser abordado quando da elaboração de um diagnóstico simples, exceto pela preocupação em se apresentar a perspectiva integradora da abordagem (bio)geográfica. Estariam aqui presentes a mesma preocupação em se definir a área de influência do projeto impactante; a escala de análise a ser adotada; a localização geral (considerações sobre o conjunto da região) e contextualização geográfica da área a ser diagnosticada; uma descrição sucinta da atividade impactante, principalmente no que disser respeito às resultantes espaciais dos impactos potencialmente previstos.

Com relação ao meio físico, as áreas de conhecimento a serem abordadas são velhas conhecidas da Geografia Física. Mesmo a geologia, cuja importância é inquestionável (principalmente se levarmos em consideração os impactos decorrentes da atividade mineradora), caminha lado a lado com a geomorfologia e a hidrologia, sendo base para a explicação de vários fenômenos que porventura venham a ocorrer. Importa aqui que tais áreas de conhecimento sejam analisadas de forma integrada, buscando-se enfatizar aqueles aspectos que estabeleçam ligações diretas entre os diversos subsistemas do meio físico. Neste sentido, por exemplo, o clima não deve ser analisado pelo clima em si, mas sim no que ele refletir na morfogênese, na pedogênese e no regime hidrológico, sem perder de vista, obviamente, o seu importante papel enquanto fator ecológico para toda a biota. A geomorfologia, por sua vez, deve ser entendida enquanto interface dinâmica do embasamento geológico e a ação modeladora do clima, da água e da própria biota. A água devce ser focalizada a partir da perspectiva de que está em movimento contínuo no sistema, modelando o relevo, regulando o clima, acelerando a pedogênese e sendo elemento fundamental para a manifestação e desenvolvimento da vida. Os solos, por sua vez, devem ser entendidos enquanto produto da ação conjunta de todos os outros elementos incluindo aí também o papel decisivo dos seres vivos enquanto fornecedores de toda fração orgânica dos mesmos. Dir-se-ia que os solos constituem-se naquele elemento do meio natural que traduz a transição entre o meio biótico e o meio abiótico. A geologia, finalmente, deve. ser sentida enquanto esqueleto físicoquímico para a geomorfologia, da mesma forma que a meteorologia o é para a climatologia.

Pode ser percebido, na perspectiva integradora exposta acima, o papel importante exercido pela biota enquanto um dos principais elementos definidores da paisagem física da grande maioria dos ambientes. Se considerarmos a vegetação como o mais "geográfico" dos elementos bióticos (fixa na paisagem; base da cadeia alimentar; abrigo para a fauna; facilmente quantificável em termos de biomassa, consumo e produção de energia e biodiversidade), percebemos a importância da inclusão do seu estudo na Geografia Física, importância esta que não pode ser relegada, da maneira como acontece quando se faz um diagnóstico separatista, nos termos espostos na figura 1 . O estudo 
da vegetação, portanto, deve ser integrado ao dos demais elementos do meio físico para que assim se possa chegar a um "zoneamento"da área em estudo, zoneamento este que deve ser entendido como uma tentativa de microregionalização, qualquer que seja o tamanho da área considerada no diagnóstico (dificilmente chegaríamos a alguma mesoregionalização). Este zoneamento será fundamental na medida em que é através dele que se pode estabelecer uma "ponte metodológica"entre a perspectiva biológica de se estudar o meio biótico e a perspectiva geográfica de se estudar o meio físico. É através dele que se pode uniformizar a linguagem utilizada entre os diversos especialistas das ciências biológicas (botânicos, zoólogos e microbiólogos, principalmente) envolvidos no diagnóstico, e torná-la compatível com a linguagem utilizada na análise ambiental do meio físico. Para tanto, todo encaminhamento metodológico utilizado pelos biólogos deve levar em consideração aquele zoneamento. É em função dele que os postos de coleta e os pontos de amostragem para levantamento da flora e da fauna devem ser definidos.

Geralmente, o estudo do meio biótico é dividido entre o estudo dos ecossistemas terrestres, no qual ênfase é dada à vegetação (flora e fitossociologia) e a macrofauna (entomofauna e cordados), e o estudo dos ecossistemas aquáticos, com ênfase nos parâmetros físico-químicos da água, e nos microorganismos aquáticos (bactérias, fungos, algas, protozoários, metazoários inferiores, formas larvais e, eventualmente, peixes). Qualquer que seja o grupo de seres vivos estudado, os biólogos lançam mão de técnicas de amostragem e/ou coleta de material de modo a proceder a análises quali-quantitativas com base nas espécies encontradas e suas respectivas populações. O objetivo central é buscar parâmetros que qualifiquem o ambiente estudado, principalmente através da identificação e análise dos chamados indicadores biológicos. Um problema que pode decorrer desta estratégia de análise refere-se à própria escala em que são processadas tais coletas e/ou amostragens. Muitas vezes, os resultados obtidos conduzem a análises que se resumem às áreas de coleta e/ou amostragem. Poucas inferências são feitas com relação ao restante da área e, muito menos, quase nada é dito comrelação aos diversos elementos do meio físico. Acabam surgindo várias análises de resultados pontuais, ou que se reduzem a transectos, sem que extrapolações sejam feitas considerando o conjunto ambiental de toda a área. Além do mais, a ausência de um zoneamento norteador quanto à definição da posição dos postos de coleta e/ou amostragem pode levar a uma miríade de pontos sem relação entre si espalhados pela área, propiciando resultados difíceis de serem aproveitados nos termos de uma análise (bio)geográfica global.

No âmbito da estrutura de diagnóstico ambiental proposta para o meio biótico exposta na figura 2, o mesmo deve ser caracterizado de modo a se contextualizar seus diversos ecossistemas aquáticos e terrestres. Os ecossistemas terrestres, por sua vez, devem ser descritos levando-se em consideração, principalmente, os aspectos fisionômicos e estruturais das formações vegetais da área uma vez que as mesmas constituem-se no pano de fundo onde se desenrolam as diversas interações inter e intraespecíficas dos indivíduos da fauna local. Definidas e descritas tais formações, um mapa deve ser confeccionado de modo a servir de base tanto para a localização dos pontos/postos de coleta/amostragem, como para visualização das relações espaciais existentes entre as formações vegetais, e entre essas e os demais elementos do meio físico. Quanto aos ecossistemas aquáticos, estes devem ser descritos de uma forma geral, em estreita correlação ao que já terá sido identificado quando do estudo dos recursos hídricos no âmbito do meio físico.

Definidos os pontos de amostragem a partir do zoneamento executado no contexto do meio físico, partese então para o levantamento e identificação da fauna existente. É importante ressaltar que todo este trabalho que antecede às coletas e amostragens faunísticas propriamente ditas, pode e deve ser realizado por um geógrafo, especialmente aquele que tenha uma boa base em biogeografia. É preciso que ele confira à abordagem biótica uma uniformidade e uma coerência espacial para que os resultados, estes sim a serem obtidos pelos biólogos, sejam aproveitados da melhor maneira possível.

\section{BIBLIOGRAFIA}

CAMARGO, José Carlos Godoy - Considerações a respeito da Biogeografia. Cad. Geografia, Belo Horizonte, v. 4, $n^{\circ} 5$, pp: 41-50, dez. 1993.

CHRISTOFOLETTI, Antônio. Geografia Física. Bol. de Geografia Teorética, vol II, nº 2`1/22, pp: 5-18, 1981.

MENDONÇA, Francisco. Geografia Física: Ciência Humana? Col. Repensando a Geografia. Editora Contexto, 1989.

SANTOS, Maria Juraci Ani dos. Introdução à Biogeografia. Bol. de Geografia - UEM. Ano 3, n³, pp: 59-68, 1985. 